\title{
Mechanism of hyperthyroidism-induced renal hypertrophy in rats
}

\author{
H Kobori, A Ichihara, Y Miyashita, M Hayashi and T Saruta \\ Department of Internal Medicine, School of Medicine, Keio University, 160-8582, Japan \\ (Requests for offprints should be addressed to T Saruta)
}

\begin{abstract}
It is well known that renal hypertrophy is induced by hyperthyroidism; however, the mechanism is not fully understood. We recently reported that cardiac hypertrophy in hyperthyroidism is mediated by enhanced cardiac expression of renin mRNA. The present study addresses the hypothesis that renal hypertrophy in hyperthyroidism is mediated by amplification of renal expression of renin mRNA. Twenty Sprague-Dawley rats were divided into control $(n=5)$ and hyperthyroid groups by daily intraperitoneal injections of saline vehicle or thyroxine. The hyperthyroid group was subdivided further into hyperthyroid-vehicle $(n=5)$, hyperthyroid-losartan $(n=5)$, and hyperthyroid-nicardipine $(n=5)$ groups by daily intraperitoneal injections of saline vehicle, losartan, or
\end{abstract}

nicardipine. All rats were killed at 4 weeks, and the blood and kidneys were collected. The kidney-to-body weight ratio increased in the hyperthyroid groups $(+34 \%)$. Radioimmunoassays and reverse transcriptase-polymerase chain reaction revealed increased renal renin $(+91 \%)$ and angiotensin II $(+65 \%)$ levels and enhanced renal renin mRNA expression $(+113 \%)$ in the hyperthyroid groups. Losartan and nicardipine decreased systolic blood pressure to the same extent, but only losartan caused regression of thyroxine-induced renal hypertrophy. These results suggest that thyroid hormone activates the intrarenal reninangiotensin system via enhancement of renal renin mRNA expression, which then leads to renal hypertrophy.

Journal of Endocrinology (1998) 159, 9-14

\section{Introduction}

Thyroid disorders produce several functional changes in the mammalian kidney (Bradley et al. 1974). One such change, renal hypertrophy, has been described in hyperthyroid animals (Nakamura et al. 1964, Katz \& Lindheimer 1973, Bradley et al. 1974, Stephan et al. 1982, Garcia del Rio et al. 1997). Bradley et al. (1974) reported that in vivo thyroxine-induced renal hypertrophy is associated with a rise in the mitotic index, and Stephan et al. (1982) indicated that renal hypertrophy is enhanced by thyroxine with a rise in the DNA content. However, the precise mechanism is not fully understood.

The renin-angiotensin system (RAS) basically consists of angiotensinogen, renin, angiotensin (ANG) I-converting enzyme, and ANG II receptor (Sealey \& Laragh 1990). As well, ANG II plays a prime role in the regulation of blood pressure because of its potent pressor effect (Mitchell \& Navar 1995), and it is very important in cell proliferation owing to its mitogenic actions (Gill et al. 1977, Casellas et al. 1997).

We recently reported that thyroid hormone enhances cardiac renin mRNA expression and activates the cardiac RAS, accounting for the cardiac hypertrophy in hyperthyroidism (Kobori et al. 1997b). Thus, we hypothesized that thyroid hormone amplifies renal renin mRNA expression, stimulates renal RAS, and induces renal hypertrophy in hyperthyroidism. To examine this hypothesis, the present study was done.

\section{Materials and Methods}

\section{Preparation of animals}

The experiments were approved by the University Committee on Animal Care and Use of Keio University. Twenty male Sprague-Dawley rats (150-200 g, Charles River Japan, Kanagawa, Japan) were used in the present study. They received standard laboratory chow containing $110 \mu \mathrm{mol} / \mathrm{g}$ sodium (Oriental Yeast, Tokyo, Japan) with tap water freely available. They were individually caged with a $12 \mathrm{~h}$ light : $12 \mathrm{~h}$ darkness cycle. Body weight (BW) was checked daily. Rats were divided into control and hyperthyroid (Hyper) groups by daily intraperitoneal injections of saline vehicle or thyroxine $(0 \cdot 1 \mu \mathrm{g} / \mathrm{g})$ for 4 weeks as described previously (Kobori et al. 1997a). Hyperthyroid rats were then treated with daily intraperitoneal administration of saline vehicle (Hyper+Vehicle), $5 \mu \mathrm{g} / \mathrm{g}$ losartan (Hyper+Los), or $10 \mu \mathrm{g} / \mathrm{g}$ nicardipine (Hyper+Nic) for 4 weeks as described previously (Kobori et al. 1997b). Systolic blood pressure (BP) and heart rate (HR) were measured weekly by tail-cuff plethysmography. All rats were killed by decapitation at 4 weeks. Blood was collected into tubes with and without EDTA, 
separated into plasma and serum by centrifugation at $4{ }^{\circ} \mathrm{C}$, and stored at $-20^{\circ} \mathrm{C}$. After the blood had been collected, the kidneys were removed immediately, washed in water free of ribonuclease, decapsulated, weighed, frozen in liquid nitrogen, and stored at $-20{ }^{\circ} \mathrm{C}$ until assayed.

\section{Hormone measurements in serum and plasma}

Serum levels of free triiodothyronine $\left(\mathrm{T}_{3}\right)$ were determined with a commercially available RIA kit according to the manufacturer's instructions (Amarex-MAB free $T_{3}$, Ortho-Clinical Diagnostics, Tokyo, Japan). Plasma renin activity (PRA) was determined with a commercially available RIA kit according to the manufacturer's instructions (Renin-Riabead, Dainabot, Tokyo, Japan). The plasma level of ANG II was determined with a commercially available RIA kit according to the manufacturer's instructions (Angiotensin II Radioimmunoassay Kit, Nichols Institute Diagnostics, San Juan Capistrano, CA, USA).

\section{Hormone measurements in renal tissue}

One-third of each frozen kidney was used for each of the following measurements.

The first portion of the kidney was used to measure the renal renin level as described previously (Kobori et al. 1997a). In brief, the kidney was thawed and homogenized with a Polytron (Kinematica, Littau, Switzerland) in $10 \mathrm{ml}$ buffer containing $2.6 \mathrm{mmol} / 1$ EDTA, $1.6 \mathrm{mmol} / 1$ dimercaprol, $3.4 \mathrm{mmol} / 1$ 8-hydroxyquinoline sulfate, $0 \cdot 2 \mathrm{mmol} / 1$ phenylmethylsulfonyl fluoride, and $5 \mathrm{mmol} / \mathrm{l}$ ammonium acetate. The homogenate was frozen and thawed four times, centrifuged at $20000 \boldsymbol{g}$ for $30 \mathrm{~min}$ at $4{ }^{\circ} \mathrm{C}$, and the supernatant removed. An aliquot of the supernatant was diluted 1:1000 with distilled water. As a substrate for the enzymatic reaction, $0.5 \mathrm{ml}$ of plasma obtained from nephrectomized male rats was added to the same volume of diluted solution. Renin activity was determined using the Renin-Riabead (Dainabot) as in our previous study (Ichihara et al. 1995). The renal renin level was calculated using the following formula : renal renin level (ng of ANG I/h per $\mathrm{g}$ of kidney)=renin activity (ng of ANG I/h per ml $) \times$ dilution rate $(1000 \times 2=2000) \times$ buffer volume $(10 \mathrm{ml}) /$ weight of the aliquot of the kidney assayed $(\mathrm{g})$.

The second piece of kidney was used for determination of the renal ANG II level as described previously (Kobori et al. 1997b). In brief, the kidney was thawed and homogenized in $10 \mathrm{ml}$ buffer that contained $0.1 \mathrm{~mol} / 1$ $\mathrm{HCl}$, which would inactivate endogenous tissue proteases. The homogenate was centrifuged at $20000 \boldsymbol{g}$ for $30 \mathrm{~min}$ at $4{ }^{\circ} \mathrm{C}$, and $1 \mathrm{ml}$ of the supernatant was applied immediately to an octadecasilyl-silica solid phase extraction column (Sep-Pak Plus $\mathrm{C}_{18}$ cartridge, Millipore, Bedford, MA, USA). The concentration of ANG II in the sample was determined as described above. The renal ANG II level was calculated using the following formula : renal ANG II level $(\mathrm{pg} / \mathrm{g}$ of kidney)=ANG II concentration $(\mathrm{pg} / \mathrm{ml}) \times$ buffer volume $(10 \mathrm{ml}) /$ weight of the aliquot of the kidney assayed (g).

Semiquantitative reverse transcriptase-polymerase chain reaction (RT-PCR)

Semiquantitative RT-PCR was carried out as described previously (Kobori et al. 1997a,b, Ichihara et al. 1998). Briefly, total RNA was extracted from the last piece of kidney according to the manufacturer's instructions using the Total RNA Separator Kit (Clontech, Palo Alto, CA, USA). The extracted RNA was suspended in ribonuclease-free water and quantified by measuring the absorbance at $260 \mathrm{~nm}$.

Total RNA from each kidney was reverse transcribed using the GeneAmp RNA PCR Core Kit (Perkin Elmer, Norwalk, CT, USA) according to the manufacturer's instructions.

Oligonucleotide primers were designed from the published cDNA sequences of renin (Tada et al. 1988) and glyceraldehyde-3-phosphate dehydrogenase (GAPDH) (Tso et al. 1985). GAPDH was used as an internal standard. The sequences of the renin primers are sense 5'-TGCCACCTTGTTGTGTGAGG-3' (exon 7, bases 851-870) and antisense 5'-ACCCGATGCGATTGT TATGCCG-3' (exon 9, bases 1203-1224). The sequences of the GAPDH primers are sense $5^{\prime}-$ TCCCTCAAGATTGTCAGCAA-3' (bases 492-511) and antisense 5'-AGATCCACAACGGATACATT-3' (bases 780-799). The expected sizes of the amplified renin and GAPDH PCR products are 374 and 308 bp respectively. The sense primers in each reaction were radiolabeled with $\left[\gamma-{ }^{32} \mathrm{P}\right] \mathrm{ATP}$ (Amersham International, Bucks, UK) and $\mathrm{T}_{4}$ polynucleotide kinase using the Kination Kit (Toyobo, Osaka, Japan).

Five microliters of the RT mixture were used for amplification using the GeneAmp RNA PCR Core Kit (Perkin Elmer) according to the manufacturer's instructions. Each reaction contained $25 \mathrm{nmol} \mathrm{MgCl}_{2}, 1000 \mathrm{nmol}$ $\mathrm{KCl}, 200 \mathrm{nmol}$ Tris- $\mathrm{HCl}(\mathrm{pH} 8 \cdot 3), 3 \cdot 75 \mathrm{pmol}$ and $10^{6}$ c.p.m. of each sense primer, $3.75 \mathrm{pmol}$ of each antisense primer, and 0.625 U of AmpliTaq DNA polymerase. To minimize nonspecific amplification, we used a 'hot start' procedure in which PCR samples were placed in a thermocycler (DNA Thermal Cycler 480, Perkin Elmer) prewarmed to $94{ }^{\circ} \mathrm{C}$. After $2 \mathrm{~min}$, PCR was performed for 35 cycles using a $30 \mathrm{~s}$ denaturation step at $94{ }^{\circ} \mathrm{C}$, a $1 \mathrm{~min}$ annealing step at $57^{\circ} \mathrm{C}$, and a $1 \mathrm{~min} 15 \mathrm{~s}$ extension step at $72^{\circ} \mathrm{C}$. We added a final $5 \mathrm{~min}$ extension step at $72^{\circ} \mathrm{C}$. After completion of RT-PCR, the DNA was electrophoresed on an $8 \%$ (weight/volume) polyacrylamide gel. Gels were dried on filter paper and then exposed to a BAS 2000 imaging plate (Fuji Film, Tokyo, 
Table 1 Effects in rats of thyroxine (Hyper), losartan (Los), and nicardipine (Nic) administration on hormone measurements and hemodynamic changes. The data are expressed as mean \pm S.E.M., $n=5$

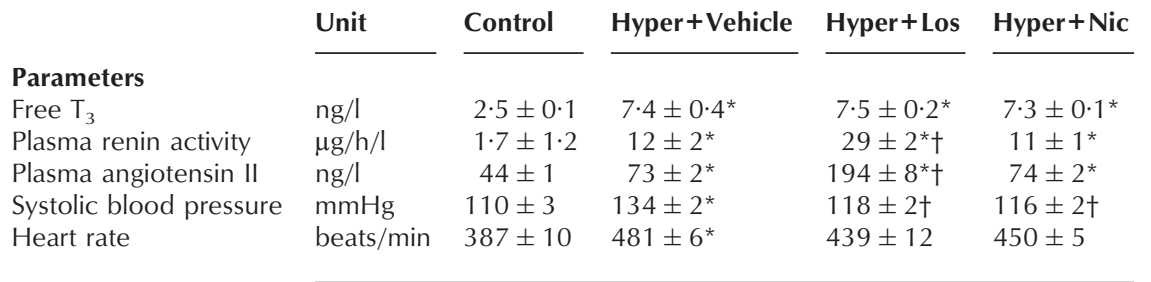

${ }^{*} P<0 \cdot 05$ vs control. $\uparrow P<0 \cdot 05$ vs Hyper + Vehicle.

Japan) for $1 \mathrm{~min}$ and quantified with a BAS 2000 Laser Image Analyzer (Fuji Film) (Amemiya \& Miyahara 1988, Itohara et al. 1990). Renin mRNA expression was evaluated as the renin/GAPDH mRNA ratio, because the levels of GAPDH mRNA did not differ between all groups.

\section{Statistical analysis}

The data are presented as mean \pm S.E.M. To compare multiple groups, we used one-way factorial analysis of variance with post hoc Scheffe's $\mathrm{F}$ test to evaluate the significance of the differences. $P<0 \cdot 05$ was considered statistically significant.

\section{Results}

Effects of administration of thyroxine, losartan and nicardipine on hormone measurements in serum and plasma

As noted in Table 1 , serum free $T_{3}$ rose significantly after intraperitoneal administration of thyroxine in the Hyper groups vs the control group. Administration of losartan and nicardipine did not affect serum free $T_{3}$.

PRA was higher in the Hyper groups vs control group. Administration of losartan elevated PRA compared with Hyper+Vehicle; however, administration of nicardipine did not affect PRA compared with Hyper+Vehicle.

Plasma ANG II was higher in the Hyper groups vs the control group. Administration of losartan elevated plasma ANG II vs Hyper+Vehicle; however, administration of nicardipine did not affect plasma ANGII compared with Hyper+Vehicle.

\section{Hemodynamic changes produced by thyroxine, losartan and nicardipine}

As shown in Table 1, there was a significant increase in systolic BP in the Hyper+Vehicle group compared with the control group. Losartan and nicardipine significantly decreased systolic BP to the same extent.

HR was significantly higher in the Hyper+Vehicle group vs the control group. Losartan and nicardipine tended to decrease HR to the same extent.

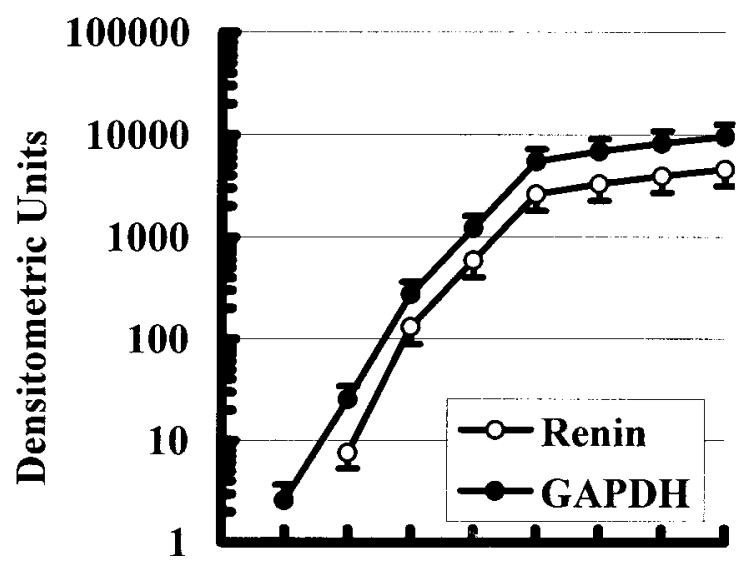

$\begin{array}{lllllllll}15 & 18 & 20 & 23 & 25 & 28 & 30 & 33 & 35\end{array}$

\section{Numbers of Cycles}

Figure 1 Cycle-dependent amplification of renin and GAPDH mRNAs in semiquantitative RT-PCR. The data are expressed as mean \pm S.E.M. $n=5$.

Effects of $R T$ on amplification of renin and GAPDH $m R N A s$

Two clear bands were detected with RT-PCR, and the bands had the predicted sizes of $374 \mathrm{bp}$ for renin and $308 \mathrm{bp}$ for GAPDH. When the PCR procedure was performed without RT, these bands were not observed and no other bands were present (data not shown). This indicated that the 374 and $308 \mathrm{bp}$ bands originated from mRNA, not from genomic DNA.

Relationship between PCR cycle number and quantity of amplified products for renin and GAPDH $m R N A s$

The relationship between PCR cycle number and RTPCR products was evaluated (Fig. 1). An exponential relationship between the number of PCR cycles and the amount of PCR product (renin and GAPDH) was 


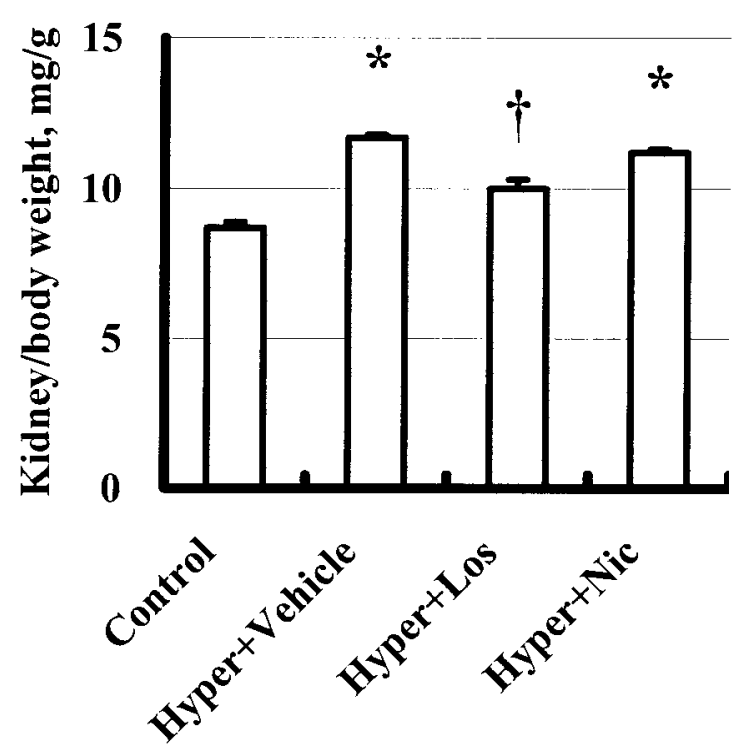

Figure 2 Changes in the ratio of KW to BW produced by thyroxine (Hyper), losartan (Los), and nicardipine (Nic) treatment. The data are expressed as mean \pm S.E.M. $n=5$. ${ }^{\star} P<0 \cdot 05$ vs control. $+P<0.05$ vs Hyper Vehicle.

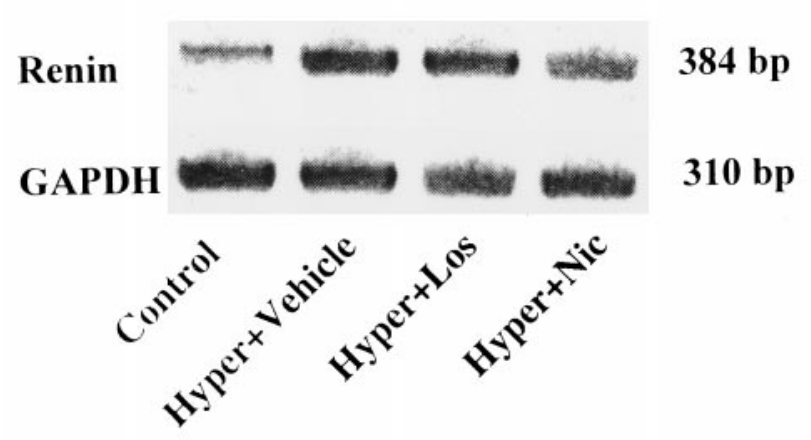

Figure 3 A representative electrophoretogram showing the effect of thyroxine (Hyper), losartan (Los), and nicardipine (Nic) treatment on renin and GAPDH mRNA levels.

obtained from cycles 23 to 28 . Twenty-five cycles of PCR were selected for the following analysis.

\section{Changes in kidneys}

As shown in Fig. 2, the ratio of the kidney weight to BW (KW/BW) was significantly increased in Hyper+Vehicle animals compared with control animals. Losartan and nicardipine significantly decreased systolic BP to the same extent; however, only losartan partially but significantly reversed the $\mathrm{KW} / \mathrm{BW}$ compared with vehicle.

As depicted in Figs 3 and 4, the renin/GAPDH mRNA ratio was increased in the Hyper groups compared with the control group. Losartan and nicardipine did not affect the renin/GAPDH mRNA ratio.

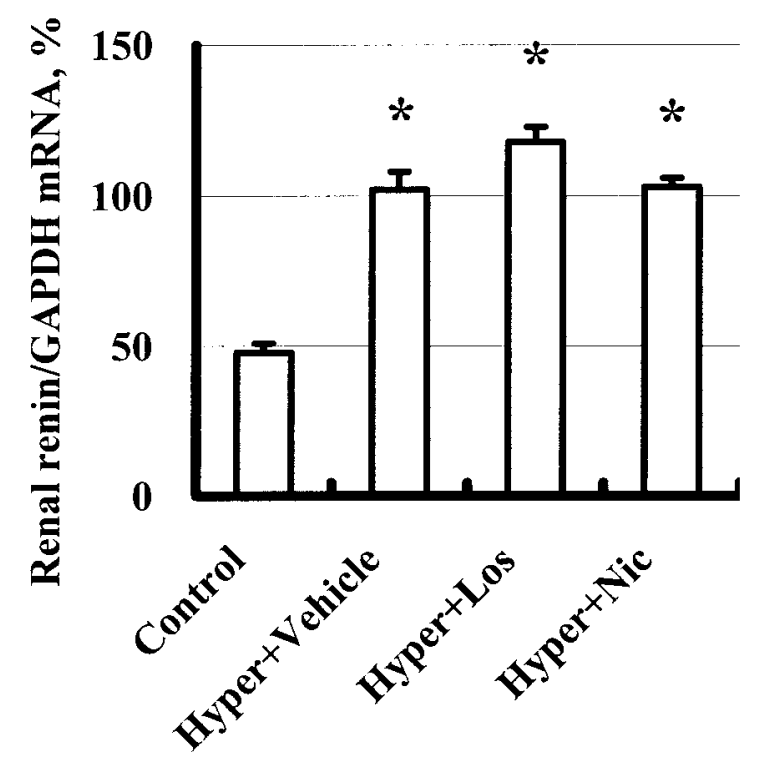

Figure 4 Changes in the ratio of renal renin mRNA expression to that of GAPDH mRNA produced by thyroxine (Hyper), losartan (Los), and nicardipine (Nic) treatment. The data are expressed as mean \pm S.E.M. $n=5$. ${ }^{*} P<0 \cdot 05$ vs control.

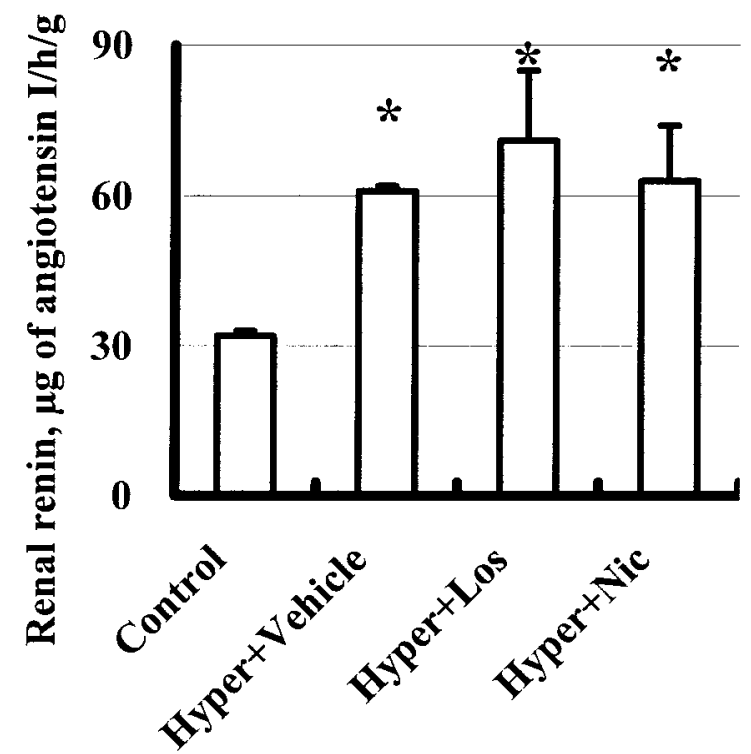

Figure 5 Changes in renal renin levels produced by thyroxine (Hyper), losartan (Los), and nicardipine (Nic) treatment. The data are expressed as mean \pm S.E.M. $n=5 .{ }^{*} P<0 \cdot 05$ vs control.

As shown in Fig. 5, renal renin levels were significantly increased in the Hyper groups vs the control group. Losartan and nicardipine did not affect renal renin levels.

As shown in Fig. 6, renal ANG II levels were significantly increased in the Hyper groups vs the control group. Nicardipine did not affect the renal ANG II levels; however, losartan decreased renal ANG II compared with Hyper+Vehicle. 


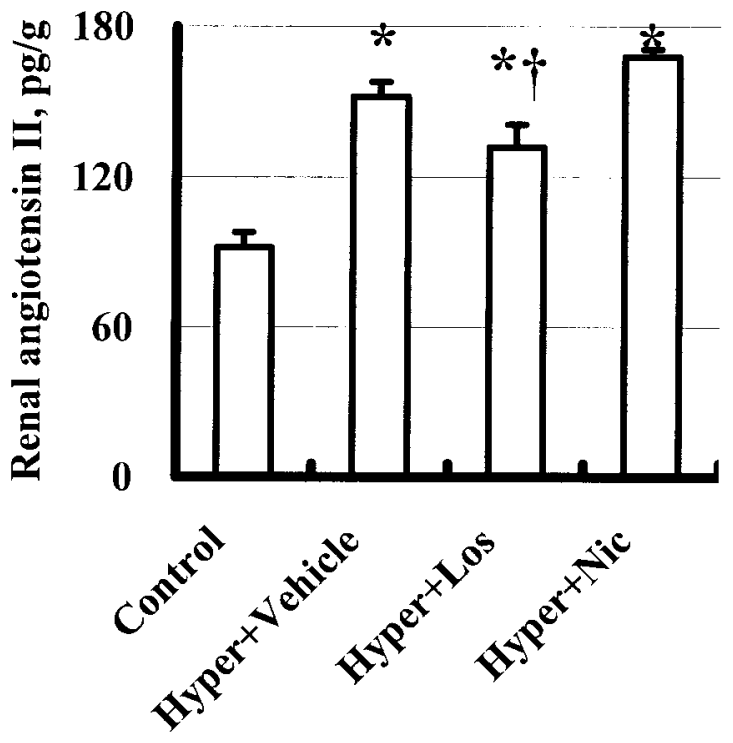

Figure 6 Changes in renal angiotensin II levels produced by thyroxine (Hyper), losartan (Los), and nicardipine (Nic) treatment. The data are expressed as mean \pm S.E.M. $n=5$. ${ }^{*} P<0 \cdot 05$ vs control. $\dagger P<0.05$ vs Hyper+Vehicle.

\section{Discussion}

Administration of thyroxine for 4 weeks significantly increased free $\mathrm{T}_{3}$, PRA, plasma ANG II, systolic BP, HR, $\mathrm{KW} / \mathrm{BW}$, renal renin mRNA expression, and renal renin and ANG II levels. These results suggest two interpretations for the mechanism of thyroxine-induced renal hypertrophy. One is that administration of thyroxine induced the activation of circulating or intrarenal RAS, which then caused renal hypertrophy. The second is that administration of thyroxine enhanced hemodynamics, which then caused renal hypertrophy. To distinguish between these possibilities, we added two experimental groups. One group had induced hyperthyroidism and was treated with the ANG II type 1 receptor antagonist, losartan. The other group had induced hyperthyroidism and was treated with the calcium channel blocker, nicardipine. In a preliminary study, the depressor effect of intraperitoneal administration of $5 \mu \mathrm{g} / \mathrm{g}$ per day losartan was equivalent to that of $10 \mu \mathrm{g} / \mathrm{g}$ per day nicardipine. Both antihypertensive drugs significantly decreased systolic BP to the same extent; however, only losartan partially but significantly reversed the $\mathrm{KW} / \mathrm{BW}$ compared with vehicle. These results do not support the latter interpretation. In other words, the mechanism of thyroxineinduced renal hypertrophy does not involve enhanced hemodynamics induced by hyperthyroidism. Accordingly, the mechanism of thyroxine-induced renal hypertrophy involves the activation of circulating or intrarenal RAS, which is mediated by the upregulation of renal expression of renin mRNA. It is well known that ANG II has potent cell proliferation effects in vitro (Gill et al. 1977) and in vivo (Casellas et al. 1997). Therefore, it is understandable that activation of RAS caused renal hypertrophy. In this study, we did not examine the mitotic index or DNA content. When we take the above discussion into consideration, we think that our results are consistent with the previous studies by Bradley et al. (1974) and Stephan et al. (1982). Bradley et al. (1974) may have observed an ANG IIinduced rise in the mitotic index, and Stephan et al. (1982) may have observed an ANG II-induced rise in the DNA content.

Which is dominant, circulating or intrarenal RAS? When compared with Hyper+Vehicle, losartan decreased the $\mathrm{KW} / \mathrm{BW}$ in accordance with a decrease in the renal ANG II level despite an increase in plasma ANG II. Nicardipine had no such effect. Consequently, enhancement of intrarenal RAS appears to be dominant in the mechanism of thyroxine-induced renal hypertrophy. The administration of losartan is known to decrease tissue levels of ANG II despite increases in plasma levels of ANG II (Mizuno et al. 1992, Kobori et al. 1997b). There are two interpretations of these data. Losartan may inhibit the internalization of ANG II in the kidneys or may inhibit de novo synthesis of ANG II in the kidneys. We were unable to distinguish these processes in this study. In other experimental models, local RAS has been shown to play a more prominent role than circulating RAS. Zou et al. (1996) recently reported that renal accumulation of circulating ANG II induces hypertension in ANG II-infused rats. Sigmund et al. (1997) recently demonstrated in transgenic mice that selective activation of an intrinsic intrarenal RAS results in hypertension via a renal ANG II-dependent, but plasma ANG II-independent, mechanism. In the same manner, the activation of local RAS may generate renal hypertrophy in our hyperthyroid rat model. Development of a more specific inhibitor of local RAS will help clarify these mechanisms.

It has been shown that selective thyroidectomy prevents the deterioration of chronic renal failure in remnant kidney models in the rat (Alfrey 1986). Conger et al. (1989) reported that the reduction in transcapillary hydraulic pressure afforded the protective mechanism of thyroidectomy in this remains model. These papers may support our hypothesis. Since thyroid hormone activates intrarenal RAS and increased renal ANG II exerts cell proliferation effects in the kidney, selective thyroidectomy probably inhibits this effect and consequently reduces transcapillary hydraulic pressure.

In conclusion, the present study demonstrated that a 4 week treatment with thyroxine caused renal hypertrophy in rats in accordance with the enhancement of renal renin mRNA expression and renal renin and ANG II levels. Additional experiments revealed that losartan, but not nicardipine, improved thyroid hormone-induced renal hypertrophy corresponding to the inhibition of renal ANG II levels. It appears that the intrarenal RAS plays an 
essential role in the development of renal hypertrophy in our hyperthyroid model. Thyroid hormone-induced enhancement of renal renin mRNA expression may be one trigger of the RAS activation that leads to renal hypertrophy.

\section{Acknowledgement}

This work was supported in part by Grant-in-Aid for Scientific Research from the Ministry of Education, Science and Culture of Japan (No. 09770500).

\section{References}

Alfrey AC 1986 Thyroid and parathyroid hormones in experimental renal failure. In The Progressive Nature of Renal Disease, 1st edn, pp 37-44. Eds BM Brenner \& JH Stein. New York: Churchill Livingstone.

Amemiya Y \& Miyahara J 1988 Imaging plate illuminates many fields. Nature 336 89-90.

Bradley SE, Stephan F, Coelho JB \& Reville P 1974 The thyroid and the kidney. Kidney International 6 346-365.

Casellas D, Bouriquet N \& Herizi A 1997 Bosentan prevents preglomerular alterations during angiotensin II hypertension. Hypertension 30 1613-1620.

Conger JD, Falk SA \& Gillum DM 1989 The protective mechanism of thyroidectomy in a rat model of chronic renal failure. American Journal of Kidney Disease 13 217-225.

Garcia del Rio C, Moreno MR, Osuna A, de Dios Luna J, Garcia-Estan J \& Vargas F 1997 Role of the renin-angiotensin system in the development of thyroxine-induced hypertension. European Journal of Endocrinology 136 656-660.

Gill GN, Ill CR \& Simonian MH 1977 Angiotensin stimulation of bovine adrenocortical cell growth. Proceedings of the National Academy of Sciences of the USA 74 5569-5573.

Ichihara A, Suzuki H, Murakami M, Naitoh M, Matsumoto A \& Saruta T 1995 Interactions between angiotensin II and norepinephrine on renin release by juxtaglomerular cells. European Journal of Endocrinology 133 569-577.

Ichihara A, Kobori H, Miyashita Y, Hayashi M \& Saruta T 1998 Differential effects of thyroid hormone on renin secretion, content, and mRNA in juxtaglomerular cells. American Journal of Physiology 274 E224-E231.

Itohara S, Farr AG, Lafaille JJ, Bonneville M, Takagaki Y, Haas W \& Tonegawa S 1990 Homing of a $\gamma \delta$ thymocyte subset with homogeneous T-cell receptors to mucosal epithelia. Nature $\mathbf{3 4 3}$ 754-757.
Katz AI \& Lindheimer MD 1973 Renal sodium- and potassiumactivated adenosine triphosphatase and sodium reabsorption in the hypothyroid rat. Journal of Clinical Investigation 52 796-804.

Kobori H, Ichihara A, Suzuki H, Miyashita Y, Hayashi M \& Saruta T 1997a Thyroid hormone stimulates renin synthesis in rats without involving the sympathetic nervous system. American Journal of Physiology 272 E227-E232.

Kobori H, Ichihara A, Suzuki H, Takenaka T, Miyashita Y, Hayashi M \& Saruta T 1997b Role of the renin-angiotensin system in cardiac hypertrophy induced in rats by hyperthyroidism. American Journal of Physiology 273 H593-H599.

Mitchell KD \& Navar LG 1995 Intrarenal actions of angiotensin II in the pathogenesis of experimental hypertension. In Hypertension: Pathophysiology, Diagnosis and Management. 2nd edn, pp 1437-1450. Eds JH Laragh \& BM Brenner. New York: Raven Press.

Mizuno K, Tani M, Hashimoto S, Niimura S, Sanada H, Watanabe H, Ohtsuki M \& Fukuchi S 1992 Effects of losartan, a nonpeptide angiotensin II receptor antagonist, on cardiac hypertrophy and the tissue angiotensin II content in spontaneously hypertensive rats. Life Sciences $\mathbf{5 1}$ 367-374.

Nakamura RM, Miyada DS, Cockett AT \& Moyer DL 1964 Thyroid and pituitary gland activity during compensatory renal hypertrophy. Experientia 20 694-696.

Sealey JE \& Laragh JH 1990 The renin-angiotensin-aldosterone system for normal regulation of blood pressure and sodium and potassium homeostasis. In Hypertension: Pathophysiology, Diagnosis and Management. 1st edn, pp 1287-1317. Eds JH Laragh \& BM Brenner. New York: Raven Press.

Sigmund CD, Ding Y, Hardy DO, Zhu L, Catterall JF \& Davisson RL 1997 Selective activation of an intrinsic intrarenal renin-angiotensin system results in hypertension via a renal angiotensin II-dependent but plasma angiotensin II-independent mechanism in transgenic mice. Journal of the American Society of Nephrology 8308 (Abstract).

Stephan F, Reville P, de Laharpe F \& Koll-Back MH 1982 Impairment of renal compensatory hypertrophy by hypothyroidism in the rat. Life Sciences 30 623-631.

Tada M, Fukamizu A, Seo MS, Takahashi S \& Murakami K 1988 Nucleotide sequence of rat renin cDNA. Nucleic Acids Research 16 3576.

Tso JY, Sun XH, Kao TH, Reece KS \& Wu R 1985 Isolation and characterization of rat and human glyceraldehyde-3-phosphate dehydrogenase cDNAs: genomic complexity and molecular evolution of the gene. Nucleic Acids Research 13 2485-2502.

Zou LX, Hymel A, Imig JD \& Navar LG 1996 Renal accumulation of circulating angiotensin II in angiotensin II-infused rats. Hypertension 27 658-662.

Received 30 March 1998

Accepted 21 May 1998 